\title{
CLINICAL ETHICS
}

\section{Are patients morally responsible for their errors?}

\author{
S Buetow, G Elwyn
}

$J$ Med Ethics 2006;32:260-262. doi: 10.1136/jme.2005.012245

Amid neglect of patients' contribution to error has been a failure to ask whether patients are morally responsible for their errors. This paper aims to help answer this question and so define a worthy response to the errors. Recent work on medical errors has emphasised system deficiencies and discouraged finding people to blame. We scrutinise this approach from an incompatibilist, agent causation position and draw on Hart's taxonomy of four senses of moral responsibility: role responsibility; capacity responsibility; causal responsibility; and liability responsibility. Each sense is shown to contribute to an overall theoretical judgment as to whether patients are morally responsible for their errors (and success in avoiding them). Though how to weight the senses is unclear, patients appear to be morally responsible for the avoidable errors they make, contribute to or can influence.

See end of article for authors' affiliations

.....................

Correspondence to: Dr S Buetow, Department of General Practice and Primary Health Care, University of Auckland, Private Bag 92019 Auckland, New Zeáland. s.buetow@auckland.ac.nz

Received 22 March 2005 In revised form

12 July 2005

Accepted for publication 13 July 2005
$\mathrm{P}$ atients "make errors too", at least that is according to the Institute of Medicine Report, written by Koln et al, To Err is Human: Building a Safer Health System. ${ }^{1}$ These errors can have serious health, and other, consequences, and the prevalence of the errors is likely to increase in the face of "greater emphasis on community based long term care, increased ambulatory surgery, shorter hospital lengths of stay, and greater reliance on complex drug therapy"' (Kohn L, p 33).

A continuing silence about patient errors has led, however, to neglect of whether patients have any moral responsibility for the (avoidable) errors they contribute to. Accepting that ordinary patients have responsibilities in health care $^{2-4}$ this paper asks whether ordinary, adult patients are morally responsible for such errors. This question, which is no less relevant to other individuals such as health professionals, has implications for defining an appropriate response to the errors.

Answering the question with respect to patients demands a moral assessment of patient error making. Such an assessment (one based on "shared" values that can "justify" actions) is typically considered to allow blame or shame for actions such as errors. The assessment tends to lead to a judgment that blame is appropriate when it is deserved (the merit based view) or is also anticipated to improve the behaviour of the person(s) making the error (the consequentialist view).

Recent work on medical errors has discouraged finding people to blame. ${ }^{1}$ There are two main reasons for this. Firstly, it has been argued that the greatest threat to patient safety does not come from errors caused freely at the "front line" by people acting with justified beliefs ("active errors"). Instead, a reduction in "latent errors", which ostensibly occur upstream and are removed from the direct control of the persons making the errors, has been reported "likely to have a greater effect on building safer systems than efforts to minimise active errors" (Kohn L, p 48). ${ }^{1}$ A limitation of this analysis is that although most medical errors are latent errors, the errors patients make are especially likely to result from their own behaviour-for example, inadvertent non-adherence through forgetfulness.

Secondly, most people, we are told, should be excused their active errors because they are human, mean well and, as applies to patients, may lack power, be sick or both. Systems theory acknowledges that individuals can be held accountable for error. This theory suggests, however, that errors result much less from personal attributes (such as sickness, anxiety, ignorance, apathy or malign intention) than suboptimal, interacting processes that mitigate personal responsibility and require redesign in order to compensate for human fallibility.

We wish to suggest that it is respectful, rather than disrespectful, to patients to consider whether, notwithstanding the influence of the systems they inhabit, patients can be morally responsible for errors and their avoidance in health care. We are only able to consider patients' moral responsibility because of our belief that ordinary adults can make reasoned choices.

Specifically, this paper is written from our incompatibilist stance (free will is incompatible with determinism) and takes an agent causation position that holds that patients can cause errors through choices freely made (these patients could have acted otherwise). Their choices neither occur by chance (they are non-random) nor are fully (deterministically) caused by prior events. Instead, these events are suggested to influence the probability with which patients make their particular choices, and so exercise some control over what they do. This agent causation account is reducible to the view that events can cause error because a patient can be known to have caused a certain error through a certain event involving this patient. Following Reason, we are defining "errors" as actions that either are not completed as intended (errors of execution) or that proceed as intended but fail to achieve the outcome intended because of a wrong plan (errors of planning). ${ }^{5}$

\section{MORAL RESPONSIBILITY}

To assess patients' moral responsibility for the errors they make or influence, we draw on 
Hart's $^{6}$ taxonomy of four forms or senses of moral responsibility: role responsibility; capacity responsibility; causal responsibility, and liability responsibility. The following discussion considers how each form, in turn, contributes to an overall theoretical judgment as to whether patients are morally responsible for their errors (and success in avoiding these). This approach assumes that these forms are objective and justifiable.

\section{Role responsibility}

Role responsibilities are defined by social roles (or sets of expected behaviours in organised social situations). These responsibilities also accommodate the claim that people become responsible through performing their roles. A challenge to this claim comes from the argument that one cannot derive an "ought" (responsibilities) from what an individual "is". Our retort is that roles obligate certain choices to back them up; otherwise these roles dissolve.

Patients have roles as consumers of care and coproducers of care. ${ }^{78}$ These roles help to define the capacity of patients to cause errors; their power or opportunity to act on this capacity; the role boundaries within which they share decision making and responsibilities; ${ }^{9}$ and any obligation they have to help avoid the errors ${ }^{8}$ they may produce, contribute to, or influence.

As consumers, patients may have a legitimised "sick role" that exempts them from their normal responsibilities until they recover or return to usual activity. ${ }^{10}$ Parsons, however, defined this sick role with reference to acute illness. His conceptualisation ignored marked variations in sick roles and norms, and disregarded patients who were not sick. Meanwhile, as coproducers, patients (along with clinical providers) deliver their own particular expertise-for example, patients tend to be experts on their own bodies, life situations, values, beliefs, and preferences. ${ }^{11}$

Even when doctors share decision making with patients ${ }^{12}$ or offer patients the information they need to select the interventions that best reflect their patient values (the informative model), ${ }^{13}$ the balance of power tends to favour the doctor. The relative lack of patient power-and other associated, common patient constraints, such as lack of health, of knowledge, of cognitive ability and of instrumental resources-can limit patients' opportunities to act on their capacities. ${ }^{14}$

Nevertheless, the potential roles of coproducer and consumer imply abilities that patients have within consultations and outside them. These roles define, firstly, a positive account of patient role responsibility. This means that this responsibility is morally necessary by virtue of the roles that individual patients are agreed to have in their situations. It is important to define these roles in a manner that incorporates the patient perspective because this perspective can be distinctive, and ultimately patients are likely to be the most affected by health care.

Secondly, the roles that patients have define their prima facie right and reciprocal moral responsibility to help reduce errors in health care. As consumers, for example, patients are likely to suffer most from the errors they and others make, perhaps giving them a special responsibility to help avoid these errors, to the extent this is possible. For such reasons, many patients have a role responsibility to participate actively in error prevention tasks that define in part their patient roles.

\section{Capacity responsibility}

As applied to patient errors, the concept of capacity responsibility focuses on the responsibility associated with patients' capacity to understand, to reason, to foresee harm and to carry out the behaviours that social (including moral) norms require of them. It supports patients' social roles, as noted above, and the competency that derives additionally from their personhood.

Within the power and resource constraints under which patients operate to different degrees, we believe that ordinary patients, firstly, typically have the capacity, in theory, to make choices freely (albeit choices that may be especially prone to errors). This capacity exists regardless of whether or not other groups permit patients to exercise it. To argue otherwise is to disrespect essential elements of patients' humanity, including their capacity for moral agency ${ }^{15}$ and their capacity to maximise control over their own lives.

Secondly, with the exception of young children and incompetent adults, patients are responsible for the choices that, in practice, they can make. The foregoing constraints may mitigate this responsibility; but since choices as such typically remain after accounting for such constraints, patients cannot reasonably deny their capacity responsibility in an attempt to escape their own freedom. From our incompatibilist position, this is because prior events in the health system do not generally predetermine patient choices. Events such as rationing-for example, do not completely remove patient choice. Rather, they tend to influence the probability of patients making certain, circumscribed choices; and this probability, if known, may reasonably determine the degree of capacity responsibility. We believe that determinism is incompatible with free will because if patients lack free will, there is no rational basis for patient morality.

To illustrate patients' capacity to make choices, consider competent patients who make "errors of execution" (their actions do not go as intended)-for example, because they forget to do certain things, such as attend for a planned consultation or bring relevant items with them, or fail to read medication labels and instructions carefully. Patients may still choose (here, with an unknown probability) to act in ways that can prevent such errors, for example by writing things down, getting into the daily habit of checking these entries, and attending carefully to instructions.

Indeed, completion of these tasks may be aided if patients view them as responsibilities. However, ordinary patients only have a capacity responsibility for themselves ${ }^{15}$ (and noncompetent dependents) and the tasks they can reasonably be expected to perform. This is because clinical providers can only be responsible to, but not for, patients. In turn, patients have a responsibility to their clinical providers to meet the requirements of their patient role.

\section{Causal responsibility}

Causal responsibility is a descriptive notion and a necessary, but not sufficient, criterion of moral responsibility. It defines responsibility retrospectively in terms of a causal relationship between the patient and error made. It is also distinct from negligence, as reflected in no fault systems of compensation, which operate, for example, in New Zealand with respect to accidents. From a merit based view, the nature of the cause of errors influences causal responsibility. Thus, patient errors, such as non-attendance for sickness, are less blameworthy if they are caused, for example, because the patient is anxious rather than apathetic or indifferent to their condition.

The possibility of knowing the root causes of medical errors defines the "causal attribution model". ${ }^{16}$ Limitations of this model include, however, its dependence on "expert opinion" and its tendency to locate errors in the structures within which people operate. This model troubles us because, as argued above, we believe that patients can contribute causally to errors, by making choices that are themselves not deterministically caused by systemic events, and may carry greater responsibility for these errors than systems perspectives tend to acknowledge. 


\section{Liability responsibility}

For Hart, ${ }^{6}$ liability responsibility signifies a form of moral responsibility for harm caused in violation of the law. Many legal systems have adopted comparative responsibility for torts. Our focus here is not, however, on legal liability but rather on how the concept of liability responsibility can be recast as personal moral responsibility for the consequences that errors have. These consequences may be positive or negative.

Positive consequences of patient errors may include the opportunity to learn from, and not repeat, the errors. Negative consequences can include adverse health outcomes that make patients sick and liable for social and financial costs to others. Such consequences may be significant-for example, patients who forget, or choose not, to report illness symptoms may compromise the effectiveness and safety of treatments. Also, it has been suggested that the magnitude of harm weights the responsibility; ${ }^{17}$ as the harm increases, so too do the moral responsibility and blameworthiness. In turn, systems of care can be redesigned to reduce the probability of patients making erroneous choices, and lessen the effects of the errors once they occur.

Blame, itself, is a consequence of errors for which patients may become morally liable. Blame is commonly reported to shackle patient safety initiatives, ${ }^{18}$ - for example, by discouraging individuals to be open about errors. However, from a consequentialist position, it may lead to desired change by deterring erroneous choices. Berwick ${ }^{19}$ has long argued that most people have good intentions. Probably so-but some patients have recurrently poor attitudes and behaviours. Primary care staff in Yorkshire reported their belief that the "patient couldn't be bothered" was a "very important reason" for approximately one in five missed appointments; and such perceptions underpinned their own interventions, "aimed mainly at punishment". ${ }^{20}$

Moreover, with the exception of the US where fear of litigation is perhaps the key reason for non-disclosure, what may deter individuals from disclosing errors is not necessarily fear of blame (or punishment) as such. This is because Western society inculcates people (via their moral conscience) to confess to wrongdoing. A locus of the nondisclosure of errors may thus be the misattribution of blame that is believed to be undeserved, unlikely to change behaviour, or both. To be effective, therefore, any ascription of blame requires the development of a cohesive community whose members respect it as a moral sanction when it is both deserved and applied equitably to strengthen people's own sense of, and ability to help prevent, error.

\section{CONCLUSION}

For Strawson, ${ }^{21}$ holding people responsible, or not, is a reactive attitude embedded in our way of life and expectation for a reasonable degree of good will. This perspective does not depend on an independent account of any theoretical conditions for responsibility. From our perspective, however, reactive attitudes can be endorsed or challenged from standpoints including theory, within and outside the practice of holding people morally responsible. From this starting point, we considered it reasonable from an agent causal, incompatibilist position to apply Hart's taxonomy to patients and their errors, concluding that, in all four senses defined by this taxonomy, patients can be morally responsible for the errors they make or contribute to. The weight to be given to these senses remains moot. Nevertheless, Savulescu ${ }^{17}$ has helped to unify them by suggesting that blameworthiness = foreseeability of harm $\mathrm{x}$ avoidability $\mathrm{x}$ magnitude of harm. ${ }^{17}$

This discussion raises awareness that patients make errors that are not necessarily the latent errors that systems approaches emphasise. This provocative position challenges the current use of systems theory to de-emphasise the "free will" of individual patients to produce errors for which they can be held morally responsible.

Blaming the system has replaced blaming individualswhich is a step too far because, as observed for professionals, how personal responsibility fits into a "no blame" culture is unclear. ${ }^{22}$ Though intended to protect individuals, not allowing patients to carry moral responsibility for their avoidable errors compromises their social role and personhood in the context of the systems they inhabit, and so may increase risks to patients. Blaming the system is also inappropriate because, from our perspective, system events do not deterministically cause patient errors. Recognition that patients may be morally responsible for the errors they make, contribute to, or can otherwise influence has the potential to liberate the systems and practices that can help patients and clinicians to understand, and take a coordinated approach to, managing clinical risks to patients in health care.

\section{Authors' affiliations}

S Buetow, Department of General Practice and Primary Health Care, University of Auckland, Auckland, New Zealand

G Elwyn, Centre for Health Sciences Research, Cardiff University, 56-57 Park Place, Cardiff, Wales

Sources of support: This research was made possible by the salary funding provided by ProCare Health Limited.

\section{REFERENCES}

1 Kohn L, Corrigan J, Donaldson M. To err is human: building a safer health system. Washington, DC: National Academy Press, 2000.

2 Buetow S. The scope for the involvement of patients in their consultations with health professionals: rights, responsibilities and preferences of patients. J Med Ethics 1998;24:243-7.

3 Draper H, Sorell T. Patients' responsibilities in medical ethics. Bioethics 2002; 16:335-52.

4 Buetow S. High need patients receiving targeted entitlements: what responsibilities do they have in primary health care? J Med Ethics 2005;31:304-6.

5 Reason J. Human error. Cambridge: Cambridge University Press, 2002.

6 Hart H. Punishment and responsibility. In: Johnson D, Snapper J, eds. Ethical issues in the use of computers. Belmont, CA: Wadsworth Publishing, 1985

7 Buetow S. Towards a new understanding of provider continuity. Ann Fam Med 2004;2:509-11.

8 Vincent C, Coulter A. Patient safety: what about the patient? Qual Saf Health Care 2002;11:76-80.

9 Coulter A. Partnership or partnership? BMJ 1999;319:719-20.

10 Parsons T. The social system. Glencoe, IL: Free Press, 1951.

11 Tuckett D, Boulton M, Olson C, et al. Meetings between experts: an approach to sharing ideas in medical consultations. London: Tavistock, 1985.

12 Charles C, Gafni A, Whelan T. Shared decision making in the medical encounter: what does it mean? (Or it takes at least two to tango). Soc Sci Med 1997;44:681-92.

13 Emanuel EJ, Emanuel L. Four models of the physician-patient relationship. JAMA 1992;267:2221-6.

14 Gwyn R, Elwyn G. When is a shared decision not (quite) a shared decision? Negotiating preferences in a general practice encounter. Soc Sci Med 1999;49:437-47.

15 McMillan R. Responsibility to or for in the physician-patient relationship. J Med Ethics 1995;21:112-15.

16 Perneger T. Investigating safety incidents: more epidemiology please. Int J Qual Health Care 2005;17:1-3.

17 Savulescu J. Beyond Bristol: taking responsibility. J Med Ethics 2002;28:281-2.

18 Leape L, Berwick D. Safe health care: are we up to it? BMJ 2000;320:725-6.

19 Berwick D. Continuous improvement as an ideal in health care. N Engl J Med 1989;320:53-6.

20 Husain-Gambles M, Neal RD, Dempsey O, et al. Missed appointments in primary care: questionnaire and focus group study of health professionals. Br J Gen Pract 2004;54:108-13.

21 Strawson PF. Freedom and Resentment. Proc Br Academy 1993;48:1-25.

22 Walton M. Creating a "no blame" culture: have we got the balance right? Qual Saf Health Care 2004;13:163-4. 